\title{
Industrial Engineering and Operations Management - a view from IJCIEOM 2020-2021
}

Antonio Márcio Tavares Thomé1 (D), Rafael Barbastefano² (1D, João Carlos Gonçalves dos Reis ${ }^{3}$ (D), Luiz Felipe Scavarda ${ }^{1}$ (D), Francisco Gaudêncio Mendonça Freires ${ }^{4}$ (i)

${ }^{1}$ Pontifical Catholic University of Rio de Janeiro, Rio de Janeiro, Brazil.

${ }^{2}$ Federal Center for Technological Education Celso Suckow da Fonseca, Rio de Janeiro, Brazil.

${ }^{3}$ Portuguese Military Academy, University of Aveiro, University of Lisbon, Aveiro, Lisbon, Portugal.

${ }^{4}$ Federal University of Bahia, Salvador, Brazil.

How to cite: Thomé, A.M.T., Barbastefano, R., Reis, J.C.G. et al. (2021), “Industrial Engineering and Operations Management - a view from IJCIEOM 2020-2021", Brazilian Journal of Operations \& Production Management, Vol. 18, No. 03, e20211221. https://doi.org/10.14488/BJOPM.2021.033

\section{ABSTRACT}

This Special Issue of the Brazilian Journal of Operations and Production Management (BJOPM) offers nine papers selected from the $26^{\text {th }}$ International Joint Conference on Industrial Engineering and Operations Management (IJCIEOM - 2020-2021). The conference theme was “Challenges and Trends for Sustainability in the 21st Century", looking ahead to bridge theory and practice of economic, social, and environmental sustainability. This editorial paper summarises the selected contributions of collaborative efforts of international researchers to advance knowledge in different research topics of industrial engineering and operations management.

Keywords: Sustainability, Industry 4.0, Maturity Models, Sales and Operations Planning, Case Study, Systematic Literature Reviews.

\section{INTRODUCTION}

The $26^{\text {th }}$ International Joint Conference on Industrial Engineering and Operations Management (IJCIEOM - 2020) was promoted by ABEPRO (Brazilian Association of Production Engineering) jointly with Adingor (Asociación para el Desarrollo de la Ingeniería de Organización), IISE (Institute of Industrial and Systems Engineers), AIM (European Academy for Industrial Management) and ASEM (American Society for Engineering Management). It was initially planned to be held at the Pontifical Catholic University of Rio de Janeiro (PUC-Rio) in February 2021. However, due to the Covid-19 pandemic, it became a virtual conference, and its organizing committee decided to merge IJCIEOM 2020 and IJCIEOM 2021 into one conference. Although virtual, the conference could achieve its goal of enhancing the connection between academia and industry and gathering researchers and practitioners specializing in industrial engineering and operations management.

The research papers offered in this special issue focus on operational excellence, total quality management (TQM), business analytics, artificial intelligence (Al), information technology (IT), supply chain management and integration, sales and operations planning (S\&OP), and industry 4.0. Next, this editorial introduces the papers, which were written by researchers from different countries and institutions: Brazil (the Methodist University of Piracicaba, Pontifical Catholic University of Parana, Pontifical Catholic University of Rio de

Financial support: The authors also acknowledge the support of Fundação de Amparo à Pesquisa do Estado do Rio de Janeiro - FAPERJ (210.368/2020 - SEI260003/002594/2020).

Conflict of interest: The authors have no conflict of interest to declare.

Corresponding author: mt@puc-rio.br

Received: 21 Apr 2021.

Accepted: 21 Apr 2021.

Editor: Julio Vieira Neto and Osvaldo L. G. Quelhas. 
Janeiro, Federal Fluminense University, Federal University of Paraná, Federal University of São Carlos and the Federal University of Rio Grande do Sul), Germany (Technische Hochschule Ingolstadt and the University of Münster), Italy (University of Milano), Portugal (Polytechnic of Viseu, University of Aveiro, and the University of Lisbon), Switzerland (University of St.Gallen), and the United States (University of Alabama). Additional papers from the IJCIEOM can be obtained in Thomé et al. (2020; 2021) and at http://www.abepro.org.br/proceedings/ index.asp.

\section{OVERVIEW OF THE SPECIAL ISSUE ARTICLES}

Researchers from the Institute of Technology Management of the University of St. Gallen offer the paper entitled "Analysis of the effects of Operational Excellence implementation on Inspection Outcomes in the Pharmaceutical Industry: An Empirical Study". This empirical study aims to evaluate the connection between pharmaceutical manufacturing plants' operational excellence implementation and regulatory inspection outcomes, through logistic regression models to improve resource management in manufacturing sites and laboratories exposed to a higher risk of quality non-compliance. They conclude that sites with a higher degree of implementation of their operational excellence plans and programs have better inspection outcomes.

Researchers from different Portuguese institutions (Polytechnic of Viseu, University of Aveiro, and the University of Lisbon) analyse the influence of artificial intelligence (Al) on public employment and the ways politics are reacting to it, based on the results of a systematic literature review. Al became an important issue, as public administration is constantly changing in response to new challenges, and political leaders are finding ways to restrain or regulate $\mathrm{Al}$ in public services. Additionally, scholars are raising legitimate concerns about its impacts on public employment. The paper entitled "Influence of artificial intelligence on public employment and its impact on politics: A systematic literature review" addresses this issue.

Different papers highlight the strong research connection between Brazil and Germany. For instance, the paper entitled "Implications of Industry 4.0 to companies' performance: A comparison between Brazil and Germany" was the result of an international academic partnership that embraced two universities in Brazil (Pontifical Catholic University of Parana and Federal University of Paraná) and one in Germany (Technische Hochschule Ingolstadt). This paper aims to investigate what are the main implications of Industry 4.0 technologies for production management. The study was carried out through a survey with companies of the metal-mechanic and automotive industry of the Curitiba Metropolitan Region (Brazil) and the Upper Bavaria Region (Germany) to determine the overall level of implementation of technologies commonly associated with Industry 4.0, and their respective impacts on operations performance. Analogous researches that formally discuss the implications of the Industry 4.0 technologies for production management are lacking. Most studies focus excessively on the technologies without approaching their impact on management systems. The main results reveal that the overall implementation and improvement levels of the Industry 4.0 technologies are higher in Germany than in Brazil. Regarding the technologies, the Internet of Things (IoT) presented one of the highest overall improvement levels for both regions, showing that the adoption of these technologies could bring significant improvements for all performance objectives. From a practical approach, companies that are willing to invest in new technologies can find a starting point to understand the benefits that they can achieve based on results obtained from companies that have already adopted the technologies in Brazil and Germany.

The connection between researchers from Brazil and Germany is also seen in the paper entitled "Literature Review on Maturity Models for Digital Supply Chains", which involves researchers from the University of Münster (Germany) and the Catholic University of Rio (Brazil). The paper investigates existing maturity models for digital supply chains and proposes possibilities for future research. It offers a structured literature review. Using the step-by-step guidelines provided by Thomé et al. (2016), the authors identified twenty-eight maturity 
models, each one associated with specific supply chain functions (plan, source, make, deliver, and return) or digital technology (Big data, Al, IoT), mainly in manufacturing and none embracing a comprehensive set of digital dimensions. Issues related to the quality of the proposed models, the lack of models applied to other sectors than manufacturing, and the development of maturity models covering all dimensions of digitalization of supply chains are suggestions for future research.

The paper entitled "Usage of Information Technology and Business Analytics with Sales and Operations Planning: A Systematic Literature Review" also involved researchers from Germany (University of Münster) and Brazil (Pontifical Catholic University of Rio de Janeiro). The paper's main objective is to explore the extent of the use of information technology and business analytics in the context of S\&OP. The results highlighted the dominant themes in IT, business analytics, and S\&OP. The article also has shown that maturity models include IT as a critical dimension of S\&OP. Also, the survey conducted by the authors identified that analytical techniques were developed for all major S\&OP planning tasks, from supply, production, logistics, and demand planning to financial planning. Finally, the study suggests an interesting research agenda composed of four relevant topics that deserve to be read and followed.

Researchers from the Catholic University of Rio de Janeiro offer a novel exploratory case study research in the S\&OP process applied in an audio-visual content production industry, operating under the production strategy of Engineer-To-Order (ETO), adding important empirical knowledge in little-explored areas of ETO strategies in the entertainment business. The study applies well-established contextualized S\&OP frameworks and demonstrates that in this segment of the service industry and for this production strategy, the observed S\&OP dimensions of context, inputs, structure, and process, and outcomes/results were key to manage the company's production complexity and to fulfil the companies' objectives. This article contributes to bridging the research-practice gap with important lessons to be learned by practitioners and researchers alike about applying the S\&OP process in the underresearched ETO-services' production context.

The research topic of S\&OP is also investigated in another paper, but now within a case study approach conducted by researchers from the Pontifical Catholic University of Rio de Janeiro and the Federal University of Rio Grande do Sul. The paper entitled "Sales and Operations Planning: Learning from 15 Brazilian Companies" involved empirical research in a significant number of Brazilian companies. The article's purpose was to characterize the implemented processes in sales and operations planning (S\&OP) and discuss the challenges and opportunities for improvement. The research results include a broad discussion about companies that consider "data collection" a normal task and not just a stage in the S\&OP cycle. Moreover, this research also shows that some organizations are starting to include a new stage in the S\&OP process, preceding the "Demand Planning", that is, the "Portfolio Management". The improvement opportunities are related to the "Pre-meeting" and "Executive Meeting" stages, which involve the simulation of different financial scenarios. Finally, the authors also found the studied companies did not adopt an S\&OP software, facing limitations in managing information and performing what-if analyses. The paper presents additional contributions that deserve to be highlighted and justifies further research.

Researchers from the University of Brasilia and the University of Milano partner in offering a maturity model for industry 4.0 application to inventory management in a beverage factory in Brazil. The goal of this research is to explore how improvements in industry 4.0 can improve companies' business processes, in particular the required dexterity for responsive and agile inventory management. The method applied to the companies' warehousing systems is action research. Based on a previous search in the literature for suitable Industry 4.0 maturity models, an appropriate model was identified, applied to the companies' operations and results were evaluated. The application of the maturity model resulted in the identification and development of "islands of improvement", which the authors suggest appearing to be a "side effect of implementing industry 4.0 based on maturity models."

The paper titled "Modified control chart for monitoring the variance" brings the results from joint research by the Brazilian universities of São Carlos, Federal Fluminense University, 
and the University of Alabama (US). It proposes a chart in which the process variance can be larger than the in-control variance value. The proposed Modified Control Chart aims to reduce the number of unnecessary interventions in the processes. Throughout the use of simulated data, the authors indicated the chart could detect only genuinely increases in the process variance, contributing to the prevention of unnecessary interventions and incrementing efficiency.

\section{FINAL REMARKS}

The editors believe that the papers of this special issue provide an interesting contribution to Industrial Engineering and Operations Management, with a sample of what was offered at IJCIEOM 2020-2021. Many of the papers build their contributions in different empirical research, particularly case studies. There is also a concentration of papers that conduct systematic literature reviews, a research method that has received much attention from OM scholars recently (Thomé et al., 2016). Altogether, these papers constitute a stimulating reading for different audiences, who will find new perspectives and findings, applications of alternative research methods, and new empirical contexts in different research areas, expanding the frontier of knowledge in Industrial Engineering and Operations Management.

\section{ACKNOWLEDGEMENTS}

The editors of this special issue would like to thank the support and incentive of Dr. Osvaldo Luiz Gonçalves Quelhas, editor-in-chief of the Brazilian Journal of Operations and Production Management, and academic societies that promoted the event. The editors would also like to thank the reviewers of this special issue and the authors of the selected papers for their great effort to maximize the academic and practice contributions of the papers and to respect the strict deadlines. The authors also acknowledge the support of Fundação de Amparo à Pesquisa do Estado do Rio de Janeiro - FAPERJ (210.368/2020 - SEI260003/002594/2020).

\section{REFERENCES}

Thomé, A.M.T., Scavarda, L.F. and Scavarda, A.J. (2016), "Conducting systematic literature review in operations management", Production Planning and Control, Vol. 27, No. 5, pp. 408-20. http://dx.doi.org/10.1080/09537287.2015.1129464.

Thomé, A.M.T., Barbastefano, R.G., Scavarda, L.F. et al., editors (2020). "Industrial Engineering and Operations Management", in IJCIEOM 2020: Springer Proceedings in Mathematics \& Statistics, vol. 337. Springer, Cham. https://doi.org/10.1007/978-3-030-56920-4.

Thomé, A.M.T., Barbastefano, R.G., Scavarda, L.F. et al., editors (2021). "Industrial Engineering and Operations Management", in IJCIEOM 2021: Springer Proceedings in Mathematics \& Statistics. Springer, Cham. (In Press).

Author contributions: All the authors contributed equally to this paper. 


\section{Biography}

Prof. A. Marcio T. Thomé is currently a Professor in the Department of Industrial Engineering at PUC-Rio, and an Affiliated Researcher at the Portuguese Catholic University at Porto - Faculty of Economics and Management. He earned a Master of Arts in Demography at Sorbonne Nouvelle - Paris University, a Master of Sciences and Doctoral degree in Industrial Engineering at PUC-Rio and was a postdoctoral fellow and visiting researcher at the University of Münster. He presently serves as President-Elect for the Global Manufacturing Research Group (GMRG) and President for GMRG Brazil. He was formerly a Population Council's Associate, Logistics and Information Systems Associate at Cambridge Consulting, Deputy Director at Westinghouse Electric Co., and Superintendent at BEMFAM-CONAPES. He is a researcher with grants by the Brazilian National Research and Development Centre (CNPq), and the Carlos Chagas Filho Foundation for Research Support of the State of Rio de Janeiro (FAPERJ). His interests are in Sustainable Supply Chain Management, Manufacturing Research, Sales and Operations Planning, and Research Methodology related areas. Prof. Thomé has over 70 scientific papers appearing in conference proceedings, book chapters and scientific journals such as Energy Policy, Resource Conservation \& Recycling, Clean Technologies and Environmental Policy, Journal of Environmental Management, Environmental Modelling and Software, Production Planning and Control, Journal of Cleaner Production, International Journal of Production Economics, International Journal of Production Research, International Journal of Operations \& Production Management, Industrial Management and Data Systems, International Journal of Project Management. He acts as Associate Editor, Management \& Production Journal, and as referee for several leading journals in sustainability and operations management. His H-index in Scopus and Web of Sciences is 18 (10.04.2021).

Links for publication record:

- https://orcid.org/0000-0001-9751-905X

- https://www.scopus.com/authid/detail.uri?authorld=55885864800

Prof. Rafael Barbastefano is a Professor of the Production Department of Federal Center of Technological Education (CEFET/RJ), and Deputy Director of the Brazilian Association of Production Engineering - ABEPRO. He earned an Undergraduate and Doctoral Degree in Production Engineering, and has a Masters Degree in Applied Mathematics by the Federal University of Rio de Janeiro (UFRJ). He has been conducting research in Social Network Analysis, Operations Management, and Engineering Education.

Links for publication record:

- https://orcid.org/0000-0001-8253-6308

- https://www.scopus.com/authid/detail.uri?authorld=6506991495

Prof. João Carlos Gonçalves dos Reis is a Professor of Operations Management, Service Science and Supply Chain Management. He received a Doctoral Diploma in Industrial Engineering (University of Aveiro, Portugal-EU) and he has been conducting scientific research in the fields of Artificial Intelligence, Service Robots, Cyber-physical Systems, Intelligent Decision Support System and Industry 4.0. He is a research fellow at the Research Center on Industrial Engineering, Management and Sustainability (EIGeS) and at the Research Unit on Governance, Competitiveness and Public Policy (GOVCOPP). He has over 55 scientific papers appearing in conference proceedings, book chapters and scientific journals, such as the International Journal of Production Economics, International Journal of Quality and Service Sciences, Journal of Sexuality and Culture, Sustainability, Heliyon, Social Sciences Journal, International Journal of Electric and Hybrid Vehicles, International Journal of Services and Operations Management, Technology in Society, Advances in Military Technology, Sustainable Futures and the Brazilian Journal of Operations and Production Management. $\mathrm{His} \mathrm{H}$-index in Scopus and Web of Sciences is 5 (10.04.2021).

Links for publication record:

- https://orcid.org/0000-0002-8504-0065

- https://www.scopus.com/authid/detail.uri?authorld=57204698523

Prof. Luiz Felipe Scavarda has joined PUC-Rio since 2002. Currently, he is the Director of the Industrial Engineering Department. He earned his Undergraduate, Master, and Doctoral 
degrees in Industrial Engineering at PUC-Rio. During 2000/2002 he joined as a visiting researcher the German Fraunhofer Institute for Manufacturing Engineering and Automation (part of his Doctoral thesis), and in 2009 he was a post-doctoral fellow at the Vienna University of Technology. From 12.2015 until 02.2017 he had a research fellowship as "Experienced Researcher" from the Alexander von Humboldt Foundation \& CAPES at the University of Münster. He has been visiting Professor and Researcher in different institutes in Germany. He has coordinated research and industrial projects sponsored by the industry sector and government agencies of different countries. Currently, he is a researcher with a grant by the Brazilian National Research and Development Centre (CNPq), a Visiting International Professor (VIP) at the University of Münster (School of Business and Economics), and a Humboldt fellow. His research interests are supply chain integration, sustainable supply chain logistics management and its related areas. He has published more than 170 articles in several conference proceedings, books and international journals as Sustainability, Resources, Conservation and Recycling, Science of the Total Environment, Journal of Cleaner Production, International Journal of Production Research, International Journal of Production Economics, and International Journal of Operations \& Production Management. His h-index is 20 at Scopus database (10.04.2021).

Links for publication record:

- https://orcid.org/0000-0002-8756-919x

- https://www.scopus.com/authid/detail.uri?authorld=6508058214

Prof. Francisco Gaudêncio Mendonça Freires was born in Fortaleza (state of Ceará Brazil) in 1974. He holds a degree in Civil Engineering from the Federal University of Ceará (1996), a Master's degree in Production Engineering from the Federal University of Santa Catarina (2000) and a Ph.D. in Industrial Engineering and Management from the Faculty of Engineering of the University of Porto (2007). He has experience in Production Engineering with emphasis on Business Logistics and Operations Management, working mainly on the following topics: Supply Chain Management, Reverse Logistics, Sustainable SCM, and Cost Management. He was a professor at the Federal University of the São Francisco Valley (UNIVASF) until 2011. He researched the issue of logistics and supply chain management of biofuels and fruit growing in the northeastern semi-arid region of Brazil. He has also developed research in the advance of the intermodal logistics of the São Francisco River and reverse logistics systems for empty pesticide packings. He is currently an Associate Professor in the Department of Mechanical Engineering at the Federal University of Bahia (UFBA) Polytechnic School. He also works in the Graduate Program in Industrial Engineering (PEI) at UFBA, currently researching renewable energy alternatives from the perspective of Supply Chain Management and Circular Economy.

Links for publication record:

- https://orcid.org/0000-0001-9622-8242

- https://www.scopus.com/authid/detail.uri?authorld=57015673300 